\title{
Progress of Physical science.
}

\author{
Oplical lllusions.
}

If we consider for a moment, in what way we may dietinguish a concave from a convex surface, we shall find that it merely consists in a different distribution of light and shade; those parts which are light in the one, being shaded in the other, and vice versit; the deception produced in objects of this form, by inverting the position of the image, is most striking, and affords one of the best instances of the fallacy of our reasoning, when we lose one of the data on which we ground our inferences.

If we take any bright convex or concave surface, no matter what the material, and place it between the window and the eye, so that the eye sees it by looking downwards at an angle of from $20^{\circ} 1060^{\circ}$, there is a certain distribution of light and shade on the object, which enables the eye, from habit, to determine whether it be convex or concave; if we can naw invert the position of the erlges of the object, with reference to the eye and the window, the shaded pirts assume just the position which would be assumed by the opposite curvature; now, this inversion may be done without any lenses whatever.

Take a common IVedgwood-ware evaporating-dish, or a common teasaucer, a basin, or any object which is concave on one side and convex on the other-a watch-olass even will do-and place it on a table between the observer and the window, with the concave side upwards, then hold a piece of common glass (with the under side blackened) in such a position that an image of the object will be rellected from its surface to the eye: the laws of optical reflection teach us that the rays from the farther edge and those from the nearer edge cross each other in their passage to the eye, and assume an inverted position, it will now be seen that the olject has every appearance of being a convex surlace, and if the angle of obzervation be well chosen, (which depends partly on the height of the window, the illusion is so strong that it can scarcely be removed from the mind. If a convex mirror be substifuted, and its position well adjusted, the distortion will present all the appearance of a concave mirror.

It is not essential to this experiment that the reflector should be black on its under surface, althougl it is more favourable for the purpose; any polished surface will suffice, provided it receives the rays at a large angle of incidence: it can be seen very well by reflection from one of the faces of a prism, and a singular effect is produced by a particular adjustment of the prism, by which two images of the same object may be conveyed to the eye within a short distance of each other; one is the regular refracted and transmitted image, and the other a reflexion from one of the internal faces of the prism: one of these images will be convex, and the other concave, and their juxtaposition forms a very remarkable appearance-one being prismatically coloured and convex, and the other of its natural coluur and concave.

If the student in optics carefully considers the law that "the angles of incidence and reflection are always equal," and will carry out that principle to it fullest extent, he will find that every one of the phenomena of which we have been treating depends solely on the operation of that law; if he considers the position of the source of illumination, the degree of curvature of the surface on which any ray falls, and the angle at which the eye re- 
ceives the refiection, he can clearly show that that law determines what part of the object will appear bright and what part shaded.

The same law determines the production of another phenomenon, as remarkable and much more beautiful than the former; if we take a plate of looking-glass, and sprinkle a few grains of dust upon it, and view it perpendicularly with one eye at a few inches distance, the dust appears arranged in a most beautiful radiating star; of which the eye is the centre; it matters not how unequally it is scattered; the symmetry is invariable.

Now in such a case as this, hefore we begin to theorize, it is proper to extend the experiment to other objects, and in accordance with this, it will be found that if the object be a polished surface of steel, of silver, of mercury, or any substance but silvered glass, no such radiating appearance presents itself; if now the student reverts to the law above alluded to, he will at once detect the cause; when the dust is scattered on the surface of silvered glass, an image of each litte particle is reflected from the mercurial surface through the glass again to the eye; as the angle at which we view any particle increises, so must the apparent distance between it and its image increase, until we arrive at $45^{\circ}$, which gives the maximum of distance.

Now the particle and its reflected image are in the same vertical plane which passes through the eye and the image of the eye; the particle, its image, and the image of the pupil of the eye appear, therefore, to be in the same right line, and as the same applies to every particle, as the line which joins the particle and its image would pass, if produced, through the image of the pupil of the eye, wherever the particle be placed, the pupil appears to be a nucleus or centre from which all these double images ex. tend radially outwards.

When, however, a polished metal is used, there is no reflecting surface from which a second image can be obtained, and we therefore see the par. ticles themselves, unaccompanied by any reflected image, and the symmetrical appearance is not then produced. 'The employment of a concave mirror affords an excellent proof that this beautiful radiating appearance is the effect of reflection. If we hold the eye at the focus of the mirror-that is, at the centre of the sphere of which the mirror is a section,-we see none of these radial lines, but as we approach near to the mirror, they gradually develop themselves; this arises from the circumstance, that when the eye is at the centre of the sphericily, incidence and reflection are both perpendicular to the mirror, or rather, the reflected imare is concealed by the particle itself, and therefore cannot reach the eye; but when we approach nearer, the images of the laleral particles becomes visible, and the atarry effect begins to appear.

In a convex mirror, the effect is very beautiful, on account of the increased obliquity which its curvature gives to the incident ray, and the nonexistence of a focal point in front of the mirror.

The effect is greatly heightened by mixing powders of two different colours-red and green, or blue and orange, for instance,-as those colours which are complementary to each other produce a singularly pleasing effect by their juxtaposition. A very slight sprinkling of milk, or any coloured liquid, likewise produces this symmetrical effect.

Instead of using glass, we may use two fluids of different densities and different refractive powers, but the two which best answer the purpose are water and mercury; if a little powder be sprinkled on the water, it will be reflected from the mercury under the water, and the same effect produced as with glass, but the latter is the more convenient of the two. 
If the eye be directed to one corner of the glass, the particles will bave the appearance of an expanded fan, emanating from that corner.

Thus may the same simple law be brought to bear upon the whole of the appearances which we have now detailed: in all these instances an object, or an assemblacre of objects, appear to be what they are not, simply from our neglecting to seek for an explanation from the only sources to which we should apply in such cases, viz, the unerring laws of Nature, the simplicity of which is as conspicuous as their beauty and their universal application.

Mag. Pop. Bei.

\section{A Ner Anemometer.}

At the late meeting of the B ritish Association at Liverpool, Mr. Ogles, of Birmingham, read an account of a new Registcring Anemome. ter and Rain Gauge, now in use at the Philosophical Institution at Birmingham, illustrated by diagratns, giving a condensed view of the observations recorded during the first eight months in the year 1837 .

In this instrument the direction of the wind is obtained by means of the vane attached to the rod, or rather tube that carries it, and consequently causes the latter to move with itself. At the lower extremity of this tube is a small pinion working in a rack, which slides backwards and forwards as the wind moves the vane, and to this rack a pencil is attached, which marks the direction of the wind on a paper ruled with the cardinal points, ans! so adjusted as to progress at the rate of one inch per hour by means of a clock. The force is at the same time ascertained by a plate one foot square, placed at right angles to the vane, supported by two light bars running on friction rollers, and communicating with a spiral spring in such a way that the plate cannot be effected by the wind's pressure, without constamly acting on this spring, and communicating the quantum of its action by a light wire, passing down the centre of the tube to another pencil, below which it thus registers its degree of force. The rain is registered at the same time by its weight acting on a balance, which moves in proportion to the quantity falling, and has also a pencil attached to it recording the result. The receiver is so arranged as to discharge every quarter of an inch that falls, when the pencil again stands at zero.

Mr. Whewell spoke highly of the construction of this anemometer; he had no doubt but that a very slight modification of the mode of registering its indications would cause it to answer every purpose which he had lately described as desirable. In its present form, however, it was the force of the aêrial current, which it indicated, not the integral effect. He also highly commended the rain-guage, and the method of showing in one diagram to the eye so many important meteorological phenomena. Professor Lloyd stated, there was a very simple method of causirg the anemometer of Mr. Osler to give the integral effect of the wind, and that was to cut out the paper covered by the tracings of the pencil indicating the force of the witd, and to weigh it; for it was easy to perceive, that since the ordinates of the curved spaces covered by those tracings were proportional to the force, and, therefore, the velocity of the wind, and the abscissie to the time, the areas represented the integrals, or the total amount of the aerial current-Mr. Eturick asked, whether some other method of supporting the cylinder which 